\section{Retrieval and representations in long-term memory}

\author{
P. R. MEUDELL \\ The University, Manchester M13 9PL, England
}

Sixty-two Ss were asked how many window panes there were in their living rooms. The time taken to respond was recorded. The results showed that recall of this information was based upon an active reconstruction of a visual image and subsequent counting of the items in the image. The rate of counting the items of the image was comparable to the rate of counting in some perceptual conditions. It is argued that both storage and retrieval may be active constructive processes.

Ever since Bartlett (1932) showed the importance of reconstructive processes in recall, psychologists have been aware that literal recall is the exception rather than the rule in human memory. It is now quite clear that Ss do not simply passively receive words at input, but rather that they organize the words into some (perhaps idiosyncratic) structure (Tulving, 1962), that they may organize the words into a story and thus achieve better recall (Bower \& Clark, 1969), and that they may also generate a visual image and use this as a retrieval cue for words (Paivio, 1969). Certainly they employ any mnemonic technique that may be available to them (Miller, Galanter, \& Pribram, 1960). Thus, there are active processes involved in memory during input (organization and structuring) and also during output (reconstructive processes). Further, the type of organization and coding used during storage is not necessarily that of the input modality, i.e., one may get a visual to verbal transformation at input (Conrad, 1964 ) or, perhaps less likely, a verbal to visual transformation as well as direct visual-visual storage and verbal-verbal storage.

The conditions under which a particular type of coding may be employed are not yet fuly known, but we can make some tentative generalizations. First, it seems fairly certain that linguistic material will be stored in an auditory-verbal form, irrespective of modality of input (Conrad, 1964). Second, since verbal coding is very efficient and economical compared to the complexity and possible irrelevant redundancy of visual storage, it is likely that much of visual input will be coded verbally (Glanzer. \& Clark, 1963). However, it seems likely that some information is stored in a visual form and that verbal coding is simply employed at the time of output (Bahrick \& Boucher, 1968), i.e., the total process of recall consists of the generation of a visual image and a response is based upon the appropriate information in the image.
The "search" part, therefore, of a memory search is, at least for the latter situation, an active constructive process. It is the purpose of this note to show an example of such a process involving the generation of visual image. Imagine you are asked the question, "How many window panes are there in your living room?" and you are required to reply with the answer as quickly as possible. If, for a number of Ss, we plotted the response latency as a function of the number of window panes reported, one of two functions would arise, depending upon the type of storage and retrieval of the information involved. In the first case, if the representation was verbal, the $\mathbf{S}$ simply has to retrieve the appropriate number and the resulting function should be flat, i.e., response latency will be a constant, independent of the numerical value of the window panes stored in memory. On the other hand,

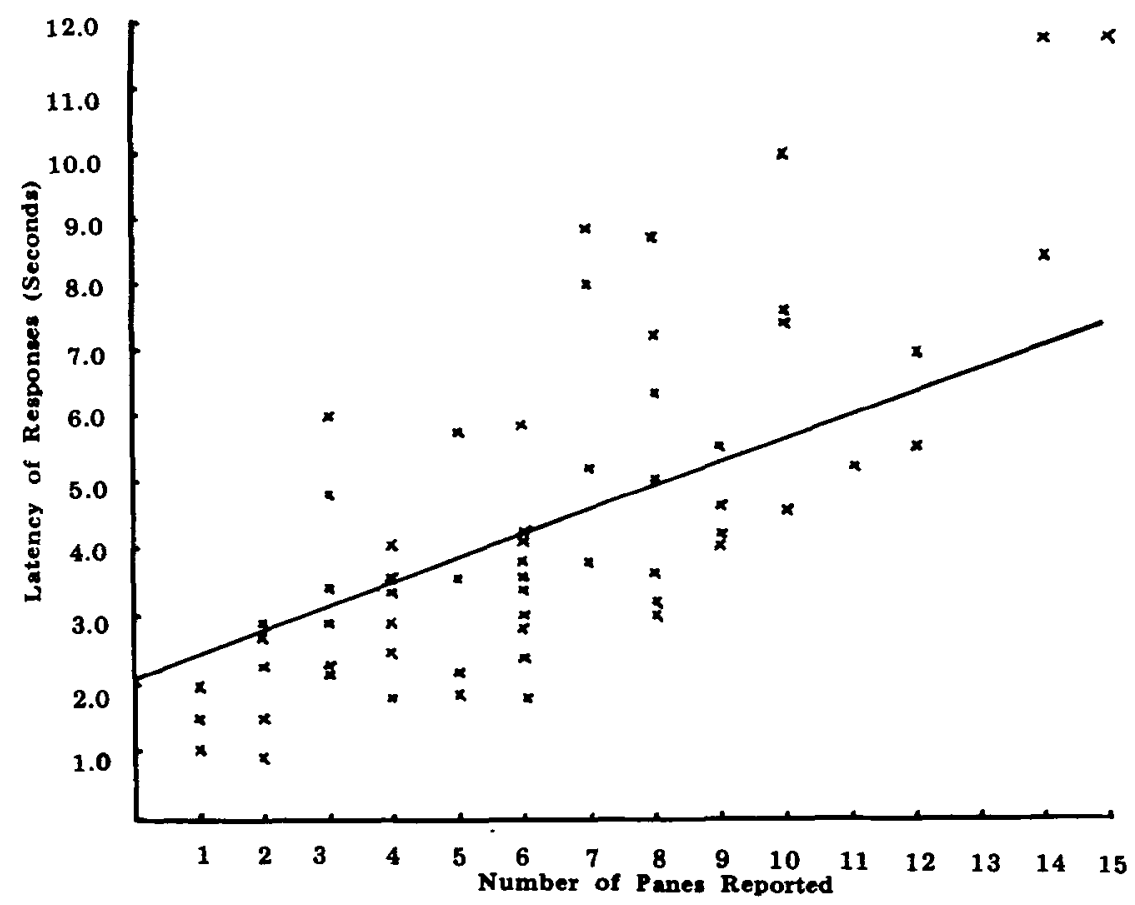

Fig. 1. Latency of response as a function of number of window panes reported. if the representation is visual, then retrieval will consist first of generation of the visual image and second of an active counting process of the panes in the image. Therefore, this function should be linear, with a slope equal to the rate of counting the window panes.

\section{METHOD}

Sixty-two students, school teachers, and university lecturers (age range: 18-40 years) were individually given the following instructions: "I am going to ask you a simple question which I want you to answer as quickly and as accurately as possible. You will know when the question has ended because you will hear the click of the stopwatch which will time how long you take to reply. Do you understand? Then here is the question: How many (slight pause) window panes are there (slight pause) in your living room?" The $E$ then started a stopwatch and stopped it when the $S$ made his response. The $\mathrm{E}$ then recorded the latency of response and the number of panes reported by the $S$ and questioned him about how he arrived at his answer.

RESULTS AND DISCUSSION

The main results are shown in Fig. 1, which shows the latenev of response for the $62 \mathrm{Ss}$ as a function of the number of window panes reported. ${ }^{1}$ The solid line drawn through the data points is the best fitting regression line; the correlation (Pearson's $r$ ) between the number of panes and latency of response was $0.52(t=4.70$, $\mathrm{d} f=60, p<.001)$. Since the 
correlation coefficient is significant, the slope of the regression line is also significant.

It seems quite clear, therefore, that, since the latency of response is an increasing function of the number of panes reported, the $S s$ in this experiment generated a visual image and then proceeded to count the panes in the image rather than simply retrieve a verbal code of the number which had previously been stored. Indeed, all the Ss reported generating a visual image but, as one might expect, only those who reported more than about five panes said that they counted; whether this is due to subitizing or extremely rapid counting (Neisser, 1967) need not concern us here, the point being that an image was generated and counting does take place if the image is sufficiently complex. It may be argued that the increase in latency has nothing to do with counting at all but is a reflection of increasing time to generate an image as the image becomes more complex, i.e., it takes longer to generate a 12-paned image than a 2-paned one. Now, while there is probably some truth in this, the Ss' reports would tend to suggest that most of the variability in the latencies is attributable to counting and not image generation. Although this does not rule out, of course, that some of the variability is due to this factor, it would suggest that it is small relative to that due to counting, and further direct estimates of image generation times show that images of letters of the alphabet can be generated at about 2.5 images/sec (Weber \& Bach, 1969).

The equation relating latency of response (L) to number of panes reported (n) is given by $\mathrm{L}=2.09+0.351 \mathrm{n}$. The slope of $351 \mathrm{msec} / \mathrm{pane}$ is a measure of counting time per item-it is not completely pure, however, since many of the Ss reported, for example, counting up one half of the image and then doubling the result. This value, then, probably underestimates the true counting time for this type of image. (The intercept of 2.09 sec presumably is made up of the time taken to encode the question, generate the appropriate image and set up the output processes.)

It is of interest to compare the counting time in this situation with that in a perceptual situation, i.e., in a situation where the objects of the count are physically present rather than being imaged as they are here. The rate of counting in perceptual (tachistoscopic) situations is a function of practice, brightness of the background, and regularity or irregularity of the objects. It is not easy to say which effects, apart perhaps from regularity, will be important in an imaged situation, but counting times in perceptual situations seem to vary from about $100 \mathrm{msec} / \mathrm{item}$ under optimum conditions to about $350 \mathrm{msec} /$ item under less than optimum conditions (Saltzman \& Garner, 1948). It would, therefore, appear that counting the items present in an image is done at about the same rate as counting in conditions of low brightness and practice in perceptual situations.

In conclusion, therefore, this experiment demonstrates that retrieval and output in long-term memory can be an active constructive process based on a visual storage of information. Indeed, the type of retrieval process involved in a memory search may be peculiar to the particular type of recall task involved (Reitman, 1970).

REFERENCES
BAHRICK, H. P. \& BOUCHER, B.
Retention of visual and verbal codes of
the same stimuli. Journal of Experimental
Psychology, $1968.78 .417-422$.
B A TLETT. F. C. Remembering.
Cambridge: Cambridge University Press,
1932.
BOWER, G. H., \& CLARK, M. C. Narrative

stories as mediators for serial learning. Psychonomic Science, 1969, 14, 181-182. CONRAD, $R$. Acoustic confusions in immediate memory. British Journal of Psychology, 1964, 55, 75-84.

GLANZER, HI., \& CLARK, W. H. Accuracy of perceptual recall: An analysis of organization. Journal of Verbal Learning \& Verbal Behavior, 1963, 1, 289-299.

MILLER、G. A., GALANTER, E., \& PRIBRAM, K. H. Plans and the structure of behavior. New York: Holt, Rinehart, \& Winston, 1960 .

NEISSER, U. Cognitive psychology. New York: Apoleton-Century-Crof ts, 1967.

PAIVIO, A. Mental imagery in associative learning and memory. Psychological Review, 1969, 76, 241-263.

REITMAN, W. What does it take to remember? in $D$. A. Norman (Ed.). Models of human memory. New York: Academic Press, 1970.

SALTZMAN, I. J., \& GARNER, W. R. Reaction time as a measure of span of attention. Journal of Psychology, 1948, $25,227-241$.

TULVING, E. Subjective organization in free recall of unrelated words. Psychological Review, 1962, 69, 344-354.

WEBER, R. J., \& BACH, M. Visual and speech imagery. British Joumal of Psychology, 1969, 60, 199-202.

\section{NOTE}

1. There were two pane latency scores at $(2.2 .8),(4,2.7)$, and $(8.5 .0)$; therefore, only 59 points are shown in Fig. 1 .

\title{
Topic importance and proportion of item agreements as significant variables in interpersonal attraction
}

\author{
PAUL G. BANIKIOTES and FLORENCE G. BANIKIOTES \\ University of Notre Dame, Notre Dame, Ind. 46556
}

The proportion of item agreements between an individual and a hypothetical stranger represented by a test protocol has been repeatedly found to be a critical variable determining interpersonal attraction. Recent work, however, has indicated that the importance of the topic or item may also be of marked significance. The purpose of this investigation was to determine how Ss respond to hypothetical strangers on the basis of information differing in both importance and proportion. Both these variables were found to have a significant effect in determining attraction.

Recent work has indicated that the variable of topic importance may be of critical significance in the determination of interpersonal attraction. Byrne \& Nelson (1964, 1965 ) found that proportion of similar attitudes had a significant effect on attraction, while topic importance did not. Findings from two other studies (Byrne, London, \& Griffitt, 1968; Clore \& Baldridge, 1968 ) indicated that importance of attitudinal topics can be a relevant variable under certain specialized conditions. These conditions occur in situations when the items are heterogeneous and when similarity is at an intermediate level between .00 and 1.00. This highly specific circumstance in which topic importance is relevant appears to be the type of situation which is most likely to exist in real life relationships. Individuals usually have heterogeneous information about others, and there is neither complete agreement nor complete disagreement. Therefore, it becomes necessary to study how topic importance and proportion of item agreements determine attraction in situations which more closely parallel 